\title{
Analysis of the road traffic-induced pollution in two areas of Sibiu, Romania
}

\author{
Cristian Deac ${ }^{1, *}$, and Marius Bibu ${ }^{1}$ \\ ${ }^{1}$ Lucian Blaga University of Sibiu, 4 E. Cioran St., 550025, Sibiu, Romania
}

\begin{abstract}
The current paper details a computer-aided research of the emission levels in two areas of the city of Sibiu, Romania. The research started from the numbers of motor vehicles passing through key segments of those two areas, located at entry points into the city of Sibiu. Using the software package Synchro Studio 7 and SimTraffic 7, the targeted crossroad areas were modelled and key indicators for the road traffic efficiency and for the emission levels were determined. These emission levels were then compared to real measured pollution values, which allowed both to assess the accuracy of the modelling and the influence of other pollution sources on the emission levels in those areas.
\end{abstract}

\section{Introduction}

Over the last few decades, the world population - and especially the urban population - has increased rapidly. This has resulted on the one hand in significantly more road traffic in the cities, with all the associated problems for the people's movement, but on the other hand also in higher levels of pollution, both in terms of noise and in terms of noxious gaseous emissions.[1]

In many cases, the problems created by pollution are enhanced by the fact that due to budgetary constraints, but often also due to practical reasons, the road infrastructure of cities is unable to adapt quickly enough to the increased demographic pressure. This problem becomes even more visible in larger towns/cities, especially when these have a certain local or regional importance.

The location analysed in this paper, the city of Sibiu, is located in central Romania and has a stable population of around 150000 inhabitants. It must be added however, that the studied city is an important industrial and commercial centre and also has a rich culture and history, so beneath the actual inhabitants there is also a significant temporary population, consisting of tourists, businessmen, workers etc., living, working or at least transiting Sibiu. All this contributes to a significant pressure on the road structure of the city, which, despite sustained efforts over the years, continues to lead to difficulties in driving through the city, but also leads to an increased pollution.

In the current paper, the authors analyse the traffic conditions and the associated noxious emissions in two key areas of Sibiu. Furthermore, using specialised software instruments, the authors offer possible solutions for an optimisation in the sense of decreasing the road traffic levels in these areas and also of decreasing the pollution levels.

\footnotetext{
* Corresponding author: cristian.deac@ulbsibiu.ro
} 


\section{Study areas, research means and method}

For the current paper, the authors have focused on two areas in Sibiu: on the one hand the area around the Unirii square in the centre of Sibiu, which represents an important crossroads area, where the north-south road traffic intersects with the east-west road traffic through the city (fig. 1) and the area around another important crossroads, this time along the Lunga street, an important artery in the northeastern part of Sibiu, which collects the traffic between the Terezian neighbourhood of Sibiu and the city centre but also the traffic between Sibiu and the other larger town in the area, Medias (fig. 2).

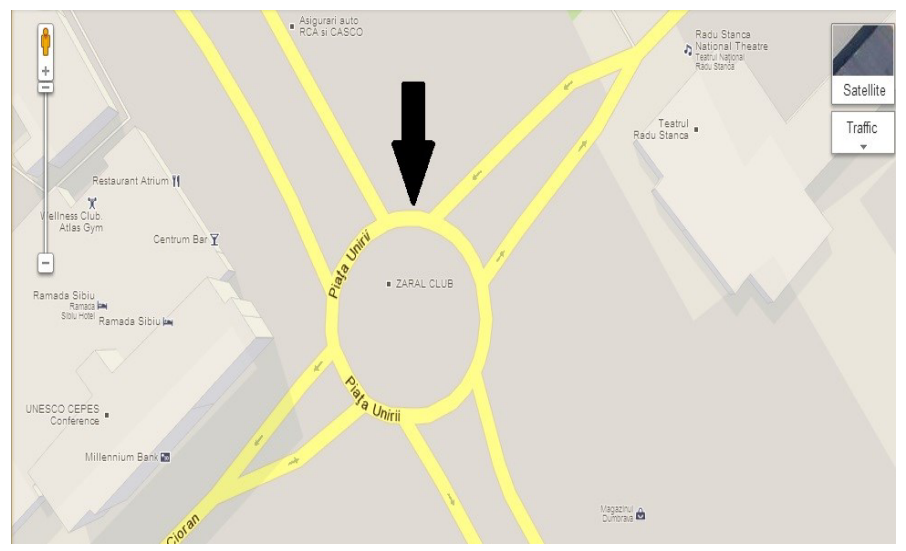

Fig. 1. The Unirii square and crossroads in central Sibiu

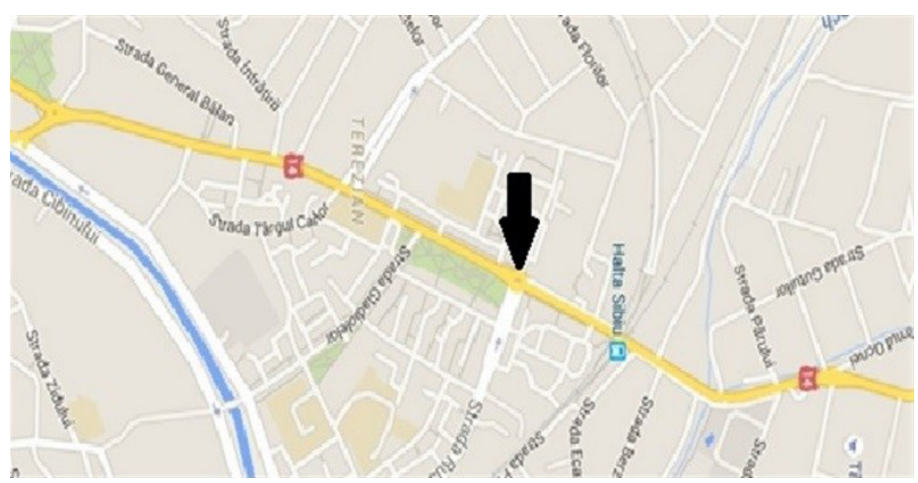

Fig. 2. The Lunga street in northeastern Sibiu, with the analysed crossroads highlighted

The first area is characterised by an intense road and pedestrian traffic for following main reasons:

- The area is of high economical and administrative interest (in or near to it there are important institutions such as banks, hotels, shopping centres, the local Police headquarters, hospitals etc., but also residential areas)

- It is crossed or bordered by several main roads that connect the various neighbourhoods in the city but also funnel the traffic towards the exits from the city and towards the surrounding cities.

The second area is located in the Terezian neighbourhood of Sibiu. It starts relatively close to the city centre, near the Cibin market and ends at the exit from Sibiu towards Medias and towards the national road DN 14. It too is bordered by residential areas, but contains also the headquarters of several important institutions or companies. 
In both areas, the current road geometry seems to be well organised, but during peak hours their traffic capacity is visibly surpassed and there is also a significant pollution mainly stemming from exhaust gases.

The analysis described in this paper intends to determine the precise traffic and pollution conditions and to find optimal solutions for reducing or possibly eliminating the mentioned problems.

The main activities that were carried out for this study included:

- analysis of the two areas;

- collection of data regarding the traffic conditions;

- modelling of the crossroads area in a specialised software and simulation of the traffic conditions;

- using the simulation software to calculate the average noxious emissions in the studied areas, based on the previously gathered traffic data;

- determining optimisation solutions for the traffic;

- analysis of the impact of the proposed solutions on the pollution in the two areas.

For collecting the data on traffic conditions, following methods can be used [2]:

- manual collection using a team of human observers

- analysis of video recordings

- collection using specialised equipment (sensors, GPS etc.)

It is important to select appropriate moments and frequencies for the collection of the traffic data. Also, these data have to be accompanied by information on factors such as the meteorological conditions, on the traffic intensity and the traffic's complexity. [2, 3]

For the current study, the data on the number of vehicles passing through the targeted areas was collected by means of video recordings, on several days, using time periods of 15 minutes each. After that, the recordings were reviewed and the vehicles were counted manually [4].

Beneath the actual car counting on each individual lane, several other elements were recorded, in order to facilitate the subsequent computer-aided modelling of the traffic in the crossroads area [4]:

- the road geometry and road equipment present (traffic lights, traffic signs etc.);

- the traffic light cycles and the corresponding durations of each colour;

- the pedestrian traffic;

- the length of waiting queues on the various directions;

- the number and frequency of the public transportation means etc.

The number of vehicles passing through the considered areas had to be "normalised" using the provisions of the Romanian standard SR 7348-2001 [5] in order to account for the different types of vehicles (small cars, motorcycles, trucks, buses etc.) noticed there, resulting in a number of so-called equivalent vehicles, calculated according to formula (1).

$$
\mathrm{N}_{\text {equiv }}=\mathrm{N}_{1} \mathrm{c}_{1}+\mathrm{N}_{2} \mathrm{c}_{2}+\ldots+\mathrm{N}_{\mathrm{i}} \mathrm{c}_{\mathrm{i}}
$$

where:

$\mathrm{N}_{\text {equiv }}$ - number of equivalent vehicles for the considered traffic flow and time period;

$\mathrm{N}_{1}, \mathrm{~N}_{2}, \ldots, \mathrm{N}_{\mathrm{i}}-$ number of vehicles of a certain type in the flow;

$\mathrm{c}_{1}, \mathrm{c}_{2}, \ldots, \mathrm{c}_{\mathrm{i}}$ - correction coefficients corresponding to each type of vehicle.

The counting revealed only relatively few motorcycles and trucks (because Sibiu has a well-organised ring road that is used by most of the heavy traffic without entering the city itself), so these vehicle categories have been neglected in the actual vehicle count.

The traffic data were then input into the specialised software package Synchro Studio 7. For this, the authors first modelled the geometry of the two areas and then the traffic-related data were added. The main element determined using this traffic simulation was the so-called 
crossroads usage capacity. This was then used as base for comparisons with the proposed optimisation solutions.

Also, the software package SimTraffic 7 was used to simulate traffic in the considered crossroads based on the data collected previously and to determine the main traffic and pollution statistics.

The optimisation of the traffic in the analysed crossroads was based on slight modifications to the crossroads' geometry, but also on modifications to other elements.

The noxious gaseous that were targeted for this analysis were hydrocarbons (HC), carbon monoxide ( $\mathrm{CO}$ ) and nitrogen oxides (NOx). The presence of hydrocarbons and carbon monoxide in vehicle exhaust is due to incomplete combustion processes, whereas NOx results when atomic oxygen formed through the thermal dissociation of molecular oxygen reacts with nitrogen molecules in the air [6].

\section{Results and discussion}

The data obtained after counting the cars passing through the Unirii crossroads during the morning hours is presented in table 1 , while the data obtained after counting the cars passing through the Lunga-Rusciorului crossroads is presented in table 2.

Table 1. Number of vehicles determined for the Unirii crossroads, on each entryway (road)

\begin{tabular}{|c|c|c|c|c|c|c|c|c|c|c|c|c|}
\hline $\begin{array}{l}\text { Road } \\
\text { Time range }\end{array}$ & & $\begin{array}{r}1 \\
\text { iil } \mathrm{Ci} \\
\text { str. }\end{array}$ & ran & & $\begin{array}{c}2 \\
\text { irii sq } \\
\text { scend }\end{array}$ & $\begin{array}{l}\text { are } \\
\text { ng) }\end{array}$ & & $\begin{array}{r}3 \\
\text { orne } \\
\text { osu I }\end{array}$ & $\begin{array}{l}\text { iu } \\
\text { Blvd. }\end{array}$ & & $\begin{array}{r}4 \\
\text { iața } U \\
\text { ascend }\end{array}$ & $\begin{array}{l}\text { iirii } \\
\text { ng) }\end{array}$ \\
\hline $\begin{array}{l}\text { Direction of } \\
\text { movement }\end{array}$ & $\leftarrow$ & $\uparrow$ & $\rightarrow$ & $\leftarrow$ & $\uparrow$ & $\rightarrow$ & $\leftarrow$ & $\uparrow \uparrow$ & $\rightarrow$ & $\leftarrow$ & $\uparrow \uparrow$ & $\rightarrow$ \\
\hline $7: 30-7: 45$ & 64 & 45 & 71 & 88 & 278 & 35 & 174 & 90 & 135 & 37 & 283 & 155 \\
\hline $7: 45-8: 00$ & 78 & 67 & 95 & 125 & 486 & 44 & 263 & 124 & 183 & 75 & 386 & 242 \\
\hline $8: 00-8: 15$ & 41 & 39 & 65 & 55 & 249 & 28 & 139 & 81 & 74 & 58 & 229 & 129 \\
\hline $8: 15-8: 30$ & 21 & 29 & 27 & 41 & 182 & 21 & 113 & 63 & 85 & 31 & 163 & 86 \\
\hline $\begin{array}{l}\text { Number of } \\
\text { buses }(\# / h)\end{array}$ & - & - & - & 13 & 12 & - & 12 & - & 13 & - & 12 & 12 \\
\hline $\begin{array}{l}\text { Number of } \\
\text { equivalent cars } \\
(7: 30-8: 30)\end{array}$ & 204 & 174 & 258 & 355 & 1237 & 128 & 731 & 358 & 523 & 201 & 1103 & 654 \\
\hline
\end{tabular}

Table 2. Number of equivalent vehicles determined for the Lunga-Rusciorului crossroads, on each entryway (road), during the morning hours

\begin{tabular}{|c|c|c|c|c|c|c|c|c|c|c|c|c|c|c|c|c|}
\hline \multicolumn{4}{|c|}{$\begin{array}{l}\text { 1. Lunga str. } \\
\text { (outwards) }\end{array}$} & \multicolumn{4}{|c|}{$\begin{array}{l}\text { 2. Rusciorului str. } \\
\text { (towards Lidl) }\end{array}$} & \multicolumn{3}{|c|}{$\begin{array}{l}\text { 3. Lunga str. } \\
\text { (towards Cibin } \\
\text { market square) }\end{array}$} & \multicolumn{3}{|c|}{$\begin{array}{l}\text { 4. Lunga str. } 2 \\
\text { (towards Cibin } \\
\text { market square }\end{array}$} & \multicolumn{3}{|c|}{$\begin{array}{l}\text { 5. Rusciorului } \\
\text { str. (towards } \\
\text { city centre) }\end{array}$} \\
\hline 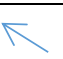 & 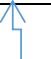 & $\uparrow$ & 7 & & & $\uparrow$ & & & $\uparrow$ & & & $\$$ & & 人 & $\uparrow$ & \\
\hline 18 & 2 & 117 & 49 & 55 & & & 103 & 7 & 101 & 13 & 1 & 3 & & 24 & 19 & 12 \\
\hline
\end{tabular}

The number of equivalent vehicles indicated in the last row of tables 1 and 2 was determined using equation 1 for each particular flow on a street (on each branch of a crossroads) and for each direction. 
The simulation of the traffic in the Unirii crossroads and in the Lunga-Rusciorului crossroads, respectively, in the initial state, carried out using the software Synchro Studio 7 lead to the calculation of the crossroads usage capacity as visualised in figures 3 and 4 .

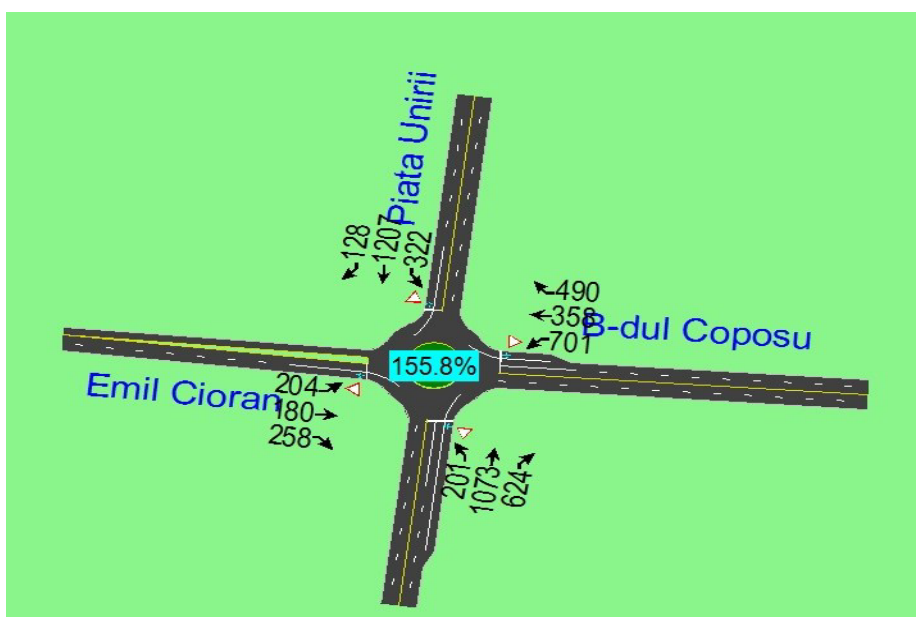

Fig. 3. Calculation of the crossroads usage capacity for the initial state of the Unirii crossroads using Synchro Studio 7

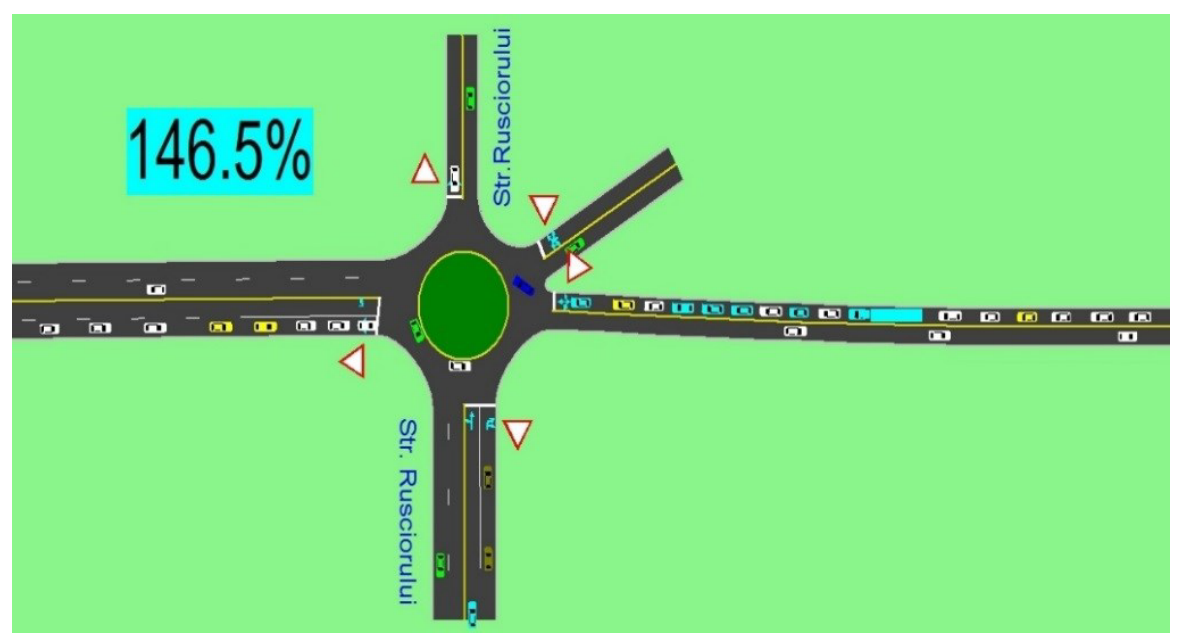

Fig. 4. Calculation of the crossroads usage capacity for the initial state of the Lunga-Rusciorului crossroads using Synchro Studio 7

As can be seen in figures 3 and 4, the crossroads usage capacity exceeds in both cases $100 \%$ by far, indicating that traffic is not unfolding under normal conditions.

Figure 5 presents the pollution statistics for the Unirii crossroads in its initial state, as calculated by the SimTraffic 7 software, while figure 6 indicates both the main road traffic and the pollution statistics for the Lunga-Rusciorului crossroads area in its initial state, also as calculated by the SimTraffic 7 software. 


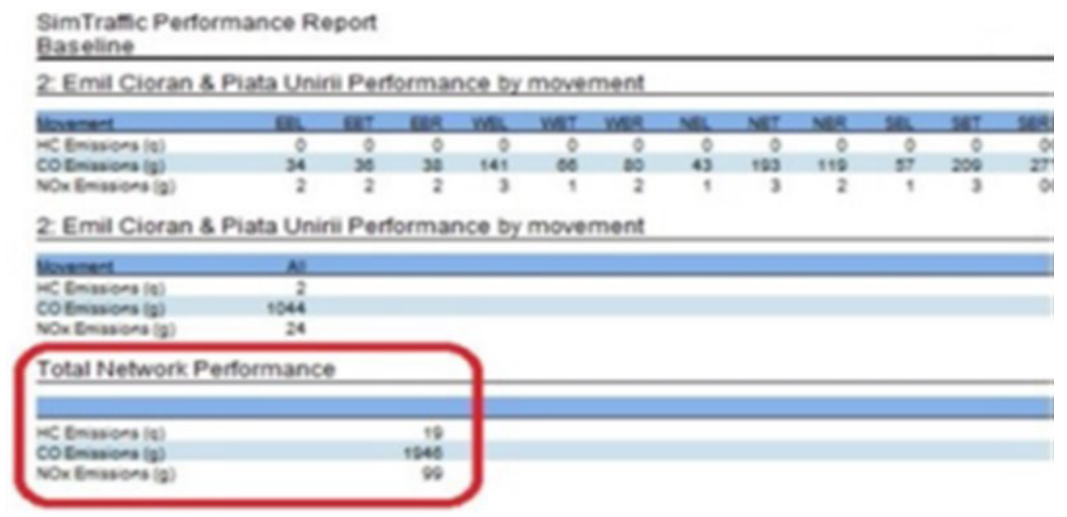

Fig. 5. Pollution statistics for the Unirii crossroads in the initial state, as determined with the SimTraffic 7 software.

\section{3: Str. Lunga \& Str. Rusciorului Performance by movement}

\begin{tabular}{|c|c|c|c|}
\hline Harest. & $\operatorname{sen} 2$ & $5 \mathrm{Wh}$ & Al \\
\hline Total Deis (Non) & 00 & 00 & 346 \\
\hline Delay / Veh (a) & 78 & 70 & 3230 \\
\hline hesesed (ko)! & 15 & 16 & 5 \\
\hline Fen Used 0 & 0.1 & 0.2 & 340 \\
\hline Farer (o) & 85 & 68 & 15 \\
\hline HCEnssoss (a) & 0 & 0 & 24 \\
\hline COEnsons $(a)$ & 5 & 13 & as? \\
\hline Nox Enasors (a) & 1 & 2 & ss \\
\hline
\end{tabular}

Total Network Performance

\begin{tabular}{|c|c|}
\hline Tota Deis (m) & 350 \\
\hline DeisyiVeh (x) & 327.2 \\
\hline kng Soted (ks) & $\theta$ \\
\hline Foriused 0 & 445 \\
\hline Futer $(Q)$ & 28 \\
\hline MC Enssons $(a)$ & 50 \\
\hline COEnasors $(\mathrm{e})$ & 2115 \\
\hline NOx Ensacrs (a) & 188 \\
\hline
\end{tabular}

Fig. 6. Road traffic and pollution statistics for the Lunga-Rusciorului crossroads in the initial state, as determined with the SimTraffic 7 software.

An analysis of the data in figures 5 and 6 shows that the three targeted pollutants have similar concentrations in the two cases, owing to vehicle numbers in roughly the same order of magnitude. The HC and NOx emissions are relatively low, but $\mathrm{CO}$ emissions are at an alarming level, which along with the general discomfort created by traffic congestion conditions call for serious and immediate corrective actions. Inhaling carbon monoxide at high concentrations can be harmful and even fatal, because $\mathrm{CO}$ prevents the transportation of oxygen through the body [6].

In order to optimise the road traffic in the area of the Unirii square, the authors suggested adding a traffic lane on a length of $50 \mathrm{~m}$ for the Unirii square (descending branch), allowing only right turns and one supplementary lane each for the Unirii square (ascending branch) and for the Coposu boulevard, at whose ends only left turns are allowed.

The optimisation possibilities of the Lunga-Rusciorului crossroads are limited by the impracticality of modifying the main problem element, namely the railroad overpass that is located just next to the crossroads, towards the exit from the city. Therefore, some alternative possibilities have been conceived: 
- one-way traffic on the Rusciorului street, on two lanes, from the city centre towards the Lidl supermarket;

- adding another traffic lane on the Lunga street, for the outward direction (this can be done at the expense of a small portion of a park located in the area);

- deviation of a part of the vehicle flow entering the city and moving towards the city centre, to the nearby Cerbului street.

After implementing these changes in the model created in Synchro Studio 7, the crossroads usage capacity changed for the Unirii square as shown in figure 7, while the new crossroads usage capacity for the Lunga-Rusciorului crossroads is shown in figure 8 .

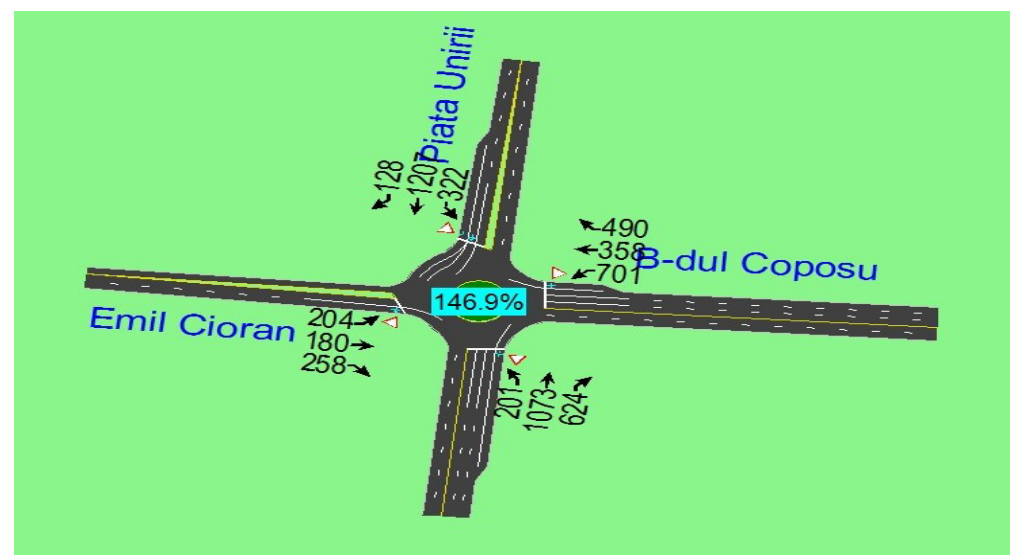

Fig. 7. Calculation of the crossroads usage capacity for the proposed changes in the Unirii crossroads

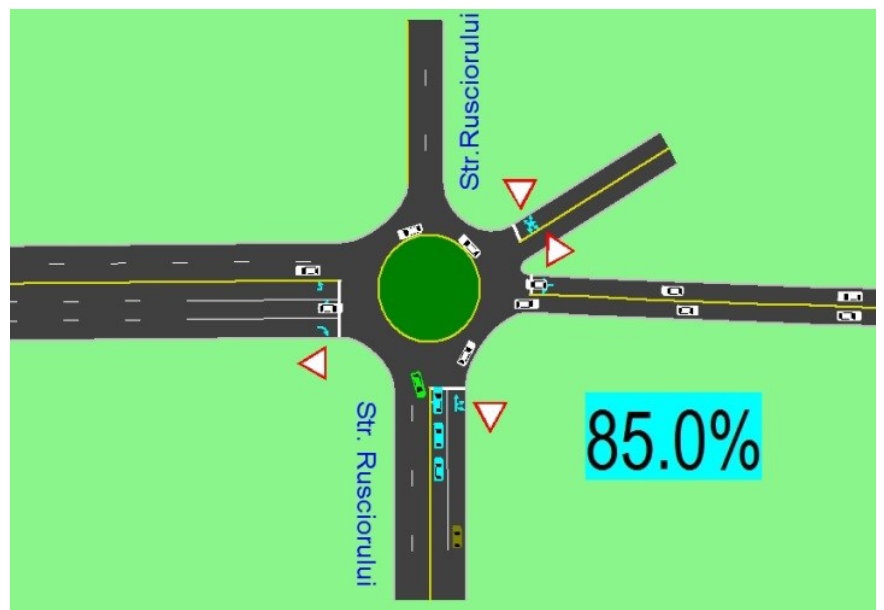

Fig. 8. New crossroads usage capacity for the Lunga-Rusciorului crossroads.

It can be seen that for the Unirii square, the proposed changes lead only to a moderate but still beneficial decrease of the crossroads usage capacity, whereas for the LungaRusciorului crossroads, the decrease is significant.

However, as can be seen in figure 9, the improved vehicle flow in the Unirii crossroads is not also beneficial for the emissions, which even increase somewhat compared to the initial state. Therefore, in this case a compromise needs to be found between a higher traffic speed and higher pollution levels. 


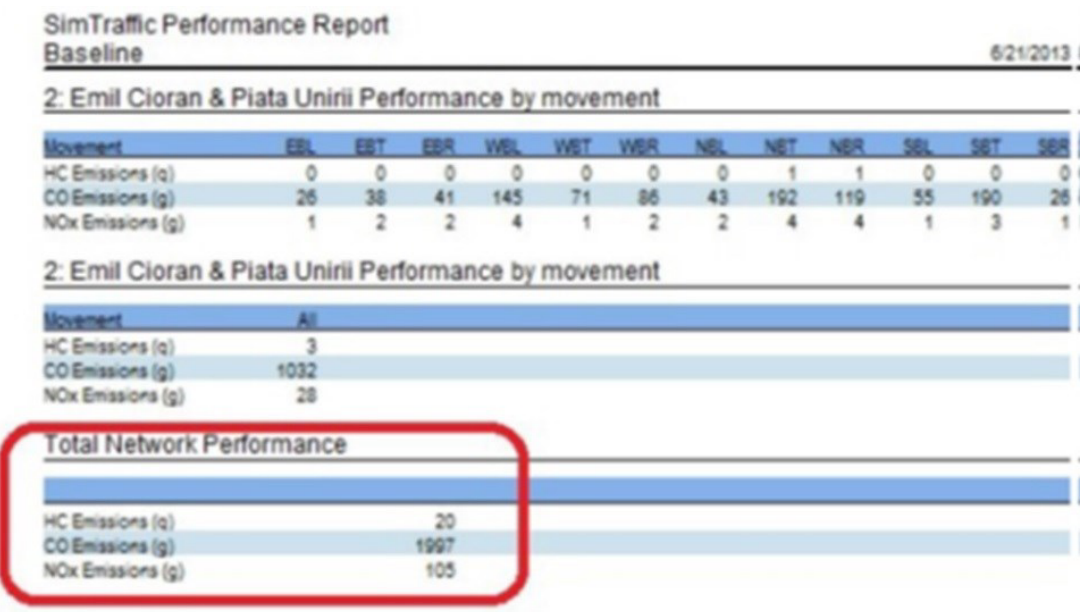

Fig. 9. Road traffic and pollution statistics for the Unirii crossroads in the optimised state, as determined with the SimTraffic software.

Owing to the much improved crossroads usage capacity in the Lunga-Rusciorului crossroads, pollution levels there also decreased significantly when applying the suggested improvements in the simulation software.

\section{Conclusions}

The current paper presented a study on the traffic and pollution conditions in two important crossroads areas from the city of Sibiu, Romania, one in the city centre and the other one towards the exit from the city towards the northeast, but both located on very busy roads.

In both cases, the proposed optimisation solutions succeeded in reducing the crossroads usage capacity, in the case of the Lunga-Rusciorului crossroads the reduction being impressive. However, the simulations carried out on solutions that increased the traffic flow have yielded mixed results in terms of reducing the road traffic-related pollution.

Therefore, any solutions targeting the improvement of traffic conditions in the city of Sibiu either need to take into account more factors and/or bolder changes even to the infrastructure (which however would lead to dramatically increased investment costs for these improvements) that would allow a simultaneous reduction of traffic problems and pollution problems, or they need to take into account compromise solutions with only modest gains - or even losses - in terms of road speed and/or pollution levels.

In future, the authors intend to extend the number of areas analysed in this manner and to work together with the local authorities and with other specialists in order to find solutions for better environmental conditions along Sibiu's main roads.

\section{References}

1. M. Wiering, J. van Veenen, J. Vreeken, and A. Koopman, Intelligent traffic light control (Institute of Information and Computing Sciences of the Utrecht University, 2004)

2. J. Barceló, M. Delgado, G. Funes, D. García, J. Perarnau, and A. Torday, SIAM News, 40, 9 (2007)

3. D. Popovici, V. Boboc, I. Galusca, Sisteme de transport şi trafic urban (Editura Societăţii Academice „Teiu Botez”, 2004)

4. M. Inta, A. Muntean, Revista Stiinta si Inginerie, 2015, http://stiintasiinginerie.ro/category/revista/2015/volumul-28/, Accessed 21.02.2017 
5. *** SR 7348-2001 Road works. Equivalation of vehicles for determining the traffic capacity (ASRO, 2001)

6. T.J. Wallington, E.W. Kaiser, J.T. Farrell, Chem. Soc. Rev. 35 (2006)

7. Scottish Environment Protection Agency, http://apps.sepa.org.uk/spripa/Pages/SubstanceInformation.aspx?pid=4, Accessed 17.03.2017 